\title{
Odour Detection Threshold Determination of Volatile Compounds in Topical Skin
} Formulations

\author{
Thomsen, Birgitte Raagaard; Hyldig, Grethe; Taylor, Robert; Blenkiron, P.; Jacobsen, Charlotte
}

Published in:

European Journal of Lipid Science and Technology

Link to article, DOI:

10.1002/ejlt.201700231

Publication date:

2018

Document Version

Peer reviewed version

Link back to DTU Orbit

Citation (APA):

Thomsen, B. R., Hyldig, G., Taylor, R., Blenkiron, P., \& Jacobsen, C. (2018). Odour Detection Threshold Determination of Volatile Compounds in Topical Skin Formulations. European Journal of Lipid Science and Technology, 120(5), [1700231]. https://doi.org/10.1002/ejlt.201700231

\section{General rights}

Copyright and moral rights for the publications made accessible in the public portal are retained by the authors and/or other copyright owners and it is a condition of accessing publications that users recognise and abide by the legal requirements associated with these rights.

- Users may download and print one copy of any publication from the public portal for the purpose of private study or research.

- You may not further distribute the material or use it for any profit-making activity or commercial gain

- You may freely distribute the URL identifying the publication in the public portal 


\section{Research Article}

\section{Odour Detection Threshold Determination of Volatile Compounds in Topical Skin} Formulations $^{\dagger}$

Thomsen, B.R. ${ }^{1 *}$, Hyldig, G. ${ }^{1}$, Taylor, R. ${ }^{2}$, Blenkiron, P. $^{2}$ \& Jacobsen, C. ${ }^{1}$

${ }^{1}$ National Food Institute, Division of Food Technology, Technical University of Denmark, Lyngby, DK, ${ }^{2}$ Glaxo Smith Kline, Brentford, UK

Correspondence: Miss Thomsen

Kgs. Lyngby

Denmark

E-mail: brath@food.dtu.dk, chja@food.dtu.dk

\section{Keywords}

lipid oxidation, skin care products, odour detection threshold values volatile oxidation products, sensory evaluation

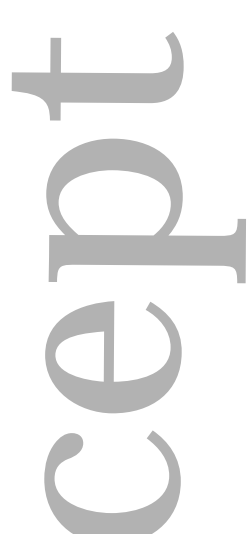

TThis article has been accepted for publication and undergone full peer review but has not been through the copyediting, typesetting, pagination and proofreading process, which may lead to differences between this version and the Version of Record. Please cite this article as doi: [10.1002/ejlt.201700231]. 
Several studies have shown that lipid oxidation can occur in topical skin formulations, but the impact of the individual volatile compounds on off-odour has not yet been determined. In this study, lipid oxidation was investigated in prototype skin care formulations. Firstly, lipid oxidation volatile compounds that increased in concentration during storage were identified. The results showed that the concentration of six volatile compounds increased above previously reported odour detection threshold values in water. These volatile compounds were selected for odour detection threshold value determination and also odour description by a trained sensory panel.

In one case, the odour detection threshold value was 50 times higher (less detectable) in skin care products than in water, whereas for other volatile compounds the odour detection threshold value was only 1.5 times higher. The odour description of the volatile compounds was, in most cases, different from that reported in literature. The observed differences are hypothesised to be due to a masking effect of the base odour of the skin care product(s), a volatile-retaining power of the base matrix and to a cocktail effect of the combined odours from different volatile oxidation products.

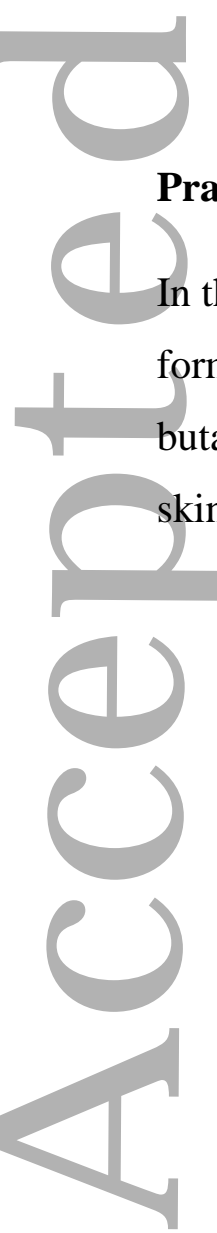

\section{Practical Applications}

In this study, the impact of volatile compounds on off-odour was explored in prototype skin care formulations. The odour detection threshold value and odour description were determined for butanal, pentanal, 3-methyl-1-butanol, 2-ethyl furan, 2-pentyl furan and 1-heptanol in prototype skin care formulations. 


\section{Introduction}

For cosmetics, product odour is known to impact consumer acceptance, product usage experience, efficacy perception and re-purchase intent. In daily life, some consumers decide whether they like a skin care product or not based on odour $[1,2]$.

Since the sensory attributes of topical skin products are vitally important to consumers, product development can be hugely challenging when including natural ingredients as key attributes such as odour, colour and product stability need to be assured [3]. A stable product not only maintains physical stability but also oxidative stability. Oxidation is considered to be one of the most important factors responsible for off-odour generation in lipid-containing foods and topical skin formulations. Off-odours, which may be caused by lipid oxidation, can spoil a product [4]. Antioxidants are often used to prevent/control lipid oxidation; however, some of the most efficient antioxidants, which ensure oxidative stability, have been restricted due to their toxicological profiles $[5,6]$.

It is important to measure how the product performs during its entire shelf life based on scientific and reproducible methodologies. Even though several highly sensitive analytical methods are available, no analytical tool can substitute the human nose. Therefore, a trained sensory panel must be used to investigate the sensory properties of topical skin formulations [7].

By using a trained odour sensory panel, it is possible to study the impact of specific volatiles including volatile lipid oxidation products on off-odour formation. It is also possible to determine the odour detection threshold (ODT) of these compounds.

Lipid oxidation has been studied widely in model-emulsions and foods, and these studies have contributed to an understanding of the analytes that are useful for indicating the progress of lipid oxidation in various products [8]. The number of studies in topical skin formulations is limited, but much of the understanding from emulsion studies can be reapplied to skin care emulsions.

Existing studies have assessed oxidative stability in skin care emulsions and simple model emulsions. In these studies, the oxidative stability was assessed by peroxide value (PV), anisidine value (AV), thiobarbituric acid reactive substances (TBARS) and colour changes [9, 10, 11]. These methods are all unspecific methods. In an earlier study we applied a combination of PV, gas chromatography-mass spectrometry (GC-MS) analysis and sensory evaluation to measure lipid oxidation during storage $[12,13]$. We identified several markers for lipid oxidation. Particularly, pentanal was found to be an excellent marker (indicator) of lipid oxidation topical skin formulations with both high and low lipid content. Whilst measuring the development of specific volatile compounds is important, it is only half the story. Understanding the ODT levels for the selected 
volatiles (in specific matrices) completes the understanding. However, ODT levels have not been studied in topical skin formulations to date.

Therefore, the purpose of this study was to determine ODT - with a trained sensory panel - for the selected volatile compounds which increased during storage or had a high concentration in two different topical skin care formulations in order to 1) obtain more exact ODT for the selected volatiles, 2) link results obtained by GC-MS to potential effects on odour properties, and 3) understand whether ODT obtained in water can be used to predict ODT in more complex systems such as topical skin care formulations.

\section{Material and methods}

Chemicals for the Bligh and Dyer method of extraction of lipids and PV determination as well as volatile standards (butanal, pentanal, 3-methyl-1-butanol, 2-ethyl furan, 2-pentyl furan and 1heptanol) used for identification were obtained from Sigma-Aldrich.

\section{Formulation Prototypes}

Skin Cream Formulation Prototype (SCFP) and Cleansing Formulation Prototype (CFP) contain a blend of lipids. The lipids included in SCFP and CFP are listed in table 1 together with the approximate lipid contents, below.

\section{$\underline{\text { Storage conditions }}$}

SCFP and CFP prototypes were stored for 6 months at $5^{\circ} \mathrm{C}, 20^{\circ} \mathrm{C}, 20^{\circ} \mathrm{C}+$ light (app 3500 lux) and $40^{\circ} \mathrm{C}$, and for 2 weeks at $50^{\circ} \mathrm{C}$. Samples were taken after $0,1 / 2,1,2,3$ and 6 months.

After sampling, all of the samples were stored at $5^{\circ} \mathrm{C}$ until analysis.

\section{Oil extraction Methodology}

The Bligh and Dyer method [14] was applied using a reduced amount of solvent as described by Iverson et al. [15]. In brief, a homogenous mixture of $20 \mathrm{ml}$ of chloroform, $20 \mathrm{ml}$ of methanol and $15 \mathrm{ml}$ of water was applied for lipid extraction from $5 \mathrm{~g}$ of topical skin formulation. By adding methanol followed by chloroform, water, methanol and water-soluble parts of the sample were separated from the lipid-soluble part. Centrifugation was then applied to complete phase separation. Thereafter, the chloroform in the lipid phase was evaporated and the oil content could be determined gravimetrically. The lipid extract was used for PV analysis. 


\section{$\underline{\text { Peroxide value }}$}

PV was measured on $2 \mathrm{~g}$ of Bligh and Dyer extract using the IDF method [16] and quantified by colorimetric determination of iron thiocyanate. It was measured on a UV mini 1240 spectrophotometer (Shimadzu, Duisburg, Germany) at $500 \mathrm{~nm}$ and reset to detect chloroform/methanol (7:3) solvent as zero.

\section{Automatic dynamic headspace collection}

Collection of volatile oxidation products from $1 \mathrm{~g}$ of topical skin formulation was performed by automatic dynamic headspace collection, transferred by thermal desorption unit/CIS [17] with the following modifications: Samples were incubated for $4 \mathrm{~min}$ in a $10 \mathrm{ml}$ vial at a temperature of $45^{\circ} \mathrm{C}$. Thereafter, the volatile compounds were collected by purging nitrogen at $50 \mathrm{ml} / \mathrm{min}$ through the headspace of the vial for $20 \mathrm{~min}$. Water was evaporated by nitrogen at $30 \mathrm{ml} / \mathrm{min}$ for $44 \mathrm{~min}$. The volatiles were transferred to a GC 6890N Series (Agilent Technologies, Santa Clara, USA) and analysed by MS 5973 inert mass-selective detector (Agilent Technologies, Santa Clara, USA). The settings for the MS were: EI mode, $70 \mathrm{eV}$, mass to charge ratio $(\mathrm{m} / \mathrm{z})$ scan between 30 and 250 . A DB1701 column (30m x ID 0.25mm x 0.5 $\mu \mathrm{m}$ film thickness, J\&W Scientific, Folsom, CA, USA) using helium gas flow $(1.3 \mathrm{ml} / \mathrm{min})$ was used for separation.

The GC temperature program was as follows: initial $45^{\circ} \mathrm{C}$ for $5 \mathrm{~min}$, then increasing with $5^{\circ} \mathrm{C} / \mathrm{min}$ to $90^{\circ} \mathrm{C}$ and then with $7^{\circ} \mathrm{C} / \mathrm{min}$ to $220^{\circ} \mathrm{C}$ and held for $4 \mathrm{~min}$ (Total run time $36,57 \mathrm{~min}$ ). The volatile compounds were identified individually by the MS-library Wiley 138K (John Wiley and Sons, Hewlett-Packard) and quantified by comparison with an external standards calibration curve. Volatile compounds that were present in the skin care products during storage were quantified. The external standards that were used for the calibration curves in the study were butanal, pentanal, 3-methyl-1-butanol, 2-ethyl furan, 2-pentyl furan and 1-heptanol.

\section{Standard addition (spiking)}

The ODT values were both determined in SCFP and CFP. A pre-experiment was conducted using an expert panel to identify the six volatile compounds detected by GC-MS in SCFP and CFP, which affected the odour the most. The expert panel estimated an ODT value for each volatile compound individually for SCFP and CFP. These ODT were subsequently used for selecting the Concentrations of the volatile compounds for assessment by the trained sensory panel. The six volatile standards selected for odour evaluation in the SCFP and CFP were: 2-ethyl furan, 2-pentyl furan, butanal, pentanal, 1-heptanol and 3-methyl-1-butanol. The standards for each of the selected 
volatile compounds were added to the SCFP and CFP in six concentrations. The lowest concentration (Conc. 1 in Table 2 and 3) was close to the ODT value of the compound in water [1828], thereafter the concentration was increased gradually just above the estimated ODT value determined in SCFP and CFP during a pre-experiment using an expert panel. The selected concentrations for ODT determination are shown in Table 2 and 3 for SCFP and CFP, respectively.

\section{$\underline{\text { Sensory evaluation }}$}

The sensory lab and test room used were compliant with national standards (ISO 8589, 1988; ISO 8586-1, 1993; ISO 11035, 1994; NMKL Procedure No. 6, 1998).

The determination of the ODT was obtained by a 3-alternative forced-choice (3AFC) according to ASTME-679, with 8-10 tested and trained assessors. The procedure for sample analysis and the statistical analysis was carried out as described in ASTME-679 in which panellists were exposed to increasing odour intensity starting at a level below odour detection limit, and then the level was gradually increased until the panellist reported that they could detect a change. During the last session, the assessors were asked to set up a set of sensory attributes that described the odour for the six volatiles. The panellists were asked to describe the overall difference caused by each of the six volatile compounds. The highest concentration of the volatile standard, Conc 6 , spiked in the prototype day cream formulation and prototype cleansing formulation was used for the free choice assessment. In each session, each assessor received 8-10 services. The assessors were instructed to evaluate the samples in the given order. Data were collected using FIZZ Network (Version 2.0, Biosystems, France).

\section{Results and discussion}

\section{$\underline{\text { Skin Cream Formulation Prototype }}$}

PV was used to measure the primary oxidation product, lipid hydroperoxides. PV were below 1 meq $/ \mathrm{kg}$ oil at day 0 and remained below $2 \mathrm{meq} / \mathrm{kg}$ during storage at $5^{\circ} \mathrm{C}, 20^{\circ} \mathrm{C}$ and $40^{\circ} \mathrm{C}$ in darkness (Figure 1), as expected due to the low lipid content of the formulation. However, storage at $20^{\circ} \mathrm{C}$ with exposure to light increased the formation of lipid hydroperoxides, as observed in other studies $[12,13]$. This pattern was also observed for the volatile aldehydes for which exposure to light resulted in an increased concentration of the aldehydes butanal and pentanal (Figures $1 \mathrm{~B}$ and 1C). The maximum concentrations of butanal and pentanal were marginally above the lowest ODT 
value reported in the literature for water, namely $9 \mathrm{ng} / \mathrm{g}$ [18-21] and $12 \mathrm{ng} / \mathrm{g}$ [19, 20, 21, 23, 24]. Therefore, it is likely that these compounds impact odour changes in the product.

In general, concentrations of 2-ethyl furan and 2-pentyl furan increased during storage at $40^{\circ} \mathrm{C}$, but were stable at $5^{\circ} \mathrm{C}$ and $20^{\circ} \mathrm{C}$. However, exposure to light seemed to initiate a further reaction or decomposition of 2-ethyl furan and 2-pentyl furan (Figures 1D and 1E). The concentration of these volatiles in SCFP stored at $40^{\circ} \mathrm{C}$ increased after 6 months above the ODT in water determined to be $2.3 \mathrm{ng} / \mathrm{g}[25,26]$ and $6 \mathrm{ng} / \mathrm{g}[18,27]$, respectively.

The concentration of 3-methyl-1-butanol was higher than for the other volatiles from the beginning of the storage period and increased further during storage at $5^{\circ} \mathrm{C}, 20^{\circ} \mathrm{C}$ and $40^{\circ} \mathrm{C}$ (Figure $1 \mathrm{~F}$ ). The concentration of 3-methyl-1-butanol was almost 10 times greater than the ODT value in water reported in literature at 250- $300 \mathrm{ng} / \mathrm{g}$ [19, 27, 28]. At this high concentration, 3-methyl-1-butanol was excepted to dominate product odour from the beginning of storage.

The last volatile compound included was 1-heptanol (Figure 1G). The concentration was low at the start of the experiment, but during storage it increased to $15 \mathrm{ng} / \mathrm{g}$ at $40^{\circ} \mathrm{C}$. This was above the odour treshold value in water at $3 \mathrm{ng} / \mathrm{g}[19,21]$.

The concentration of secondary lipid oxidation products increased most when stored at higher temperatures and exposed to light. The concentration surpassed the literature-reported ODT values observed for these volatiles in water but not in oil. Therefore, these volatile compounds may affect the odour of the product. To further evaluate the odours of the individual volatiles in the two products, a sensory odour evaluation was performed by a trained panel.

\section{Cleansing Formulation Prototype}

PV were below $1 \mathrm{meq} / \mathrm{kg}$ at day 0 and remained below $3 \mathrm{meq} / \mathrm{kg}$ during storage at $5^{\circ} \mathrm{C}, 20^{\circ} \mathrm{C}$ and $40^{\circ} \mathrm{C}$ in darkness (Figure $2 \mathrm{~A}$ ), as expected due to the low lipid content of the formulation. However, storage at $20^{\circ} \mathrm{C}$ with exposure to light increased the formation of lipid hydroperoxides significantly to approximately $20 \mathrm{meq} / \mathrm{kg}$ (Figure 2A). Similar observations have been reported earlier [12, 13] in skin care emulsions. The only secondary volatile oxidation product to increase significantly during storage was butanal, which increased to concentrations above the lowest ODT value reported in literature (for butanal dissolved in water (9 ng/g) [18-21]. In contrast to the pattern observed for PV, GC-MS results showed an increase in butanal, particularly at $40^{\circ} \mathrm{C}$ (Figure 1B). Despite low lipid hydroperoxide levels, an increase in butanal was observed during storage. This is hypothesised to be 
due to a faster conversion from primary to secondary oxidation products at elevated temperatures [20].

Since the amounts of pentanal, 2-ethylfuran, 2-pentylfuran and 1-heptanol were below their threshold values in water and/or they did not increase significantly during storage, data for the other volatile compounds are shown in supplementary material S1.

\section{Sensory odour description and odour detection threshold value of volatile compounds}

The sensory panel at DTU Food assessed (via a free text field) the odour of the volatile standards added to the two different topical skin formulations (Table 4). The odour of the volatile compounds in "concentration 6" (see table 2) differed slightly for some volatile compounds from SCFP to CFP. SCFP and CFP were assessed individually because the lipid content can affect ODTs and the odour descriptors. The similarities and differences between ODTs and odour descriptors due to formulation type were examined.

The trained sensory panel described 3-methyl-1-butanol as a sharp odour of cleaning agent in the SCFP, which was an unpleasant odour. It was sharper in the SCFP than the CFP. However, 3methyl-1-butanol gave rise to descriptors of chemical and medicinal odours in both products. This is quite different from the odour description in the literature, where it is described as balsamic, whiskey, malt or burnt [29, 30, 31, 32].

The volatile standard of 1-heptanol provided a sweet coconut odour in both products, as well as other, more different descriptors. These descriptions are also different from reports in the literature where the odour of this compound is described as mushroom [29].

2-Ethyl furan addition provided a sweet vanilla odour in both products, but also a stearin odour in the SCFP. The description in literature is not the same, although stearin may be slightly related to rubber and burnt, but not to pungent [27, 31].

Interestingly, the 2-pentyl furan addition resulted in two markedly different odours. In the SCFP, it provided a soil, moss and mushroom odour, whereas in CFP it provided a perfumed, soap flake and liquorice odour. These descriptions were similar with the description in literature where it is described as grassy, liquorice, green, bean and butter [27, 29, 31, 33].

Butanal gave rise to a cheese-like sour odour in both products. It is slightly different from the description in literature where it is described as pungent and green [29]. But the description of the 
sourness was quite different for the products. In the SCFP, it was an unpleasant sourness described as sour dishcloth and baby regurgitation. In the CFP, it was described as a pleasant citrus sourness. Pentanal gave rise to a green base odour but with two different side odours in SCFP and CFP. The side odours were flower in SCFP and acidic milk in CFP. This is quite different from literature where it is described as almond, malt, strawberry, fruit and tomato [27, 29]. Since several of the volatile compounds provided a different odour compared with the literature description of the pure volatile compounds, it can be concluded that the matrix/solvent has a large impact on the odour effects of volatile compounds. This was also concluded by Costa et al. [34].

Because the odour profiles of the volatile compounds added to the skin care products were often different from literature, the same may be the case for the ODT values. This difference may be related to an initial content of volatile compounds in both products, but may also be due to a matrix effect on the release of the volatile compounds. It is also possible that the volatiles may have a cocktail effect, which will result in a completely different odour than any of the individual volatiles.

Odour detection threshold value determined in Skin Cream Formulation and Cleansing Formulation Prototypes

The detected volatile compounds could also be present in both products before they were spiked with each volatile compound. Therefore, the exact volatile concentration could be greater than the amounts being dosed in. For that reason, the exact volatile concentrations were determined by dynamic headspace GC-MS. The ODT values for the volatile compounds are shown in Table 5.

Since 3-methyl-1-butanol was present in high concentration from the beginning of the storage period in the SCFP, it is not surprising that the exact amount measured by GC-MS was higher than the added amount. Based on the exact ODT value of $1926 \mathrm{ng} / \mathrm{g}$, it is possible that the concentration increase during storage could affect the product odour, particularly if exposed to light (3-methyl-1butanol in the SCFP ranged from $1940 \mathrm{ng} / \mathrm{g}$ up to $2465 \mathrm{ng} / \mathrm{g}$ ).

In CFP, the ODT value was lower (approximately 5x) than SCFP, which is expected because the viscosity and product odour intensity of the CFP was lower than that of the SCFP. Since the maximum concentration of 3-methyl-1-butanol observed during storage was $200 \mathrm{ng} / \mathrm{g}$ in the CFP, it will most likely not affect the product odour as an individual compound during 6 months of storage. However, a cocktail effect cannot be discounted. 
The ODT value in the SCFP was almost 10 times higher than in water (250-300 ng/g), whereas the ODT value in CFP was only approximately 1.5 times higher. This highlights the importance of determining the ODT value in specific matrices and not to apply those for water or oil.

The ODT values for 1-heptanol were the same in the SCFP and the CFP (overlapping standard deviations), it was 155 and $170 \mathrm{ng} / \mathrm{g}$ in the SCFP and CFP, respectively. This value was more than 50 times higher than the ODT value for water at $3 \mathrm{ng} / \mathrm{g}$ - again - this highlights the importance of using ODT values determined in similar matrices. These ODT values were higher than the amount found during storage. Therefore, 1-heptanol was most likely not a contributory factor to off-odour generation as an individual compound. The same was the case for 2-ethyl furan, 2-pentyl furan, butanal and pentanal. The higher ODT values vs. in a water matrix may be related to a masking effect of the base odour of the product.

As mentioned earlier, ODT values for the volatile compounds only include the individual effect and not the cocktail effect. Other scientists have found that the cocktail effect also contributed to odour changes despite the fact that ODT values of the individual compounds were not exceeded [35, 36]. More studies are needed to investigate the cocktail effect of all the volatile compounds.

GSK Toxicology group has assessed the human safety impact of the volatiles included in this report. At the determined levels these substances do not raise any toxicological concern, neither locally or systemically.

\section{Conclusion}

This investigation has shown that the product matrix in which the selected volatiles are assessed can significantly impact the ODT limit. Hence, the ODT results for the volatiles in the topical skin emulsions evaluated are different from the values reported in literature for water or oil matrices. For example, butanal increased in the CFP above the ODT value for a water matrix. However, when ODT was determined in CFP, it was significantly below the ODT in the CFP itself.

Overall, the ODT values in the formulations were higher than those for water, which was expected. However, it was surprising that 1-heptanol had a 50 times higher ODT value in the formulations than in a water matrix. This was hypothesised to be related to a masking effect of the base odour of the products and/or reaction with other compounds, which thereby increase the ODT value. Hence, this study illustrates that ODT values will be substantially higher in complex emulsion systems including both cosmetic and food emulsions than in water. However, the exact increase in ODT 
value compared to water depends on the matrix's retention of the volatile compounds or masking effects. For example, the ODT value for 3-methyl-1-butanol was almost 50 times higher in SCFP compared to CFP. All leading to the conclusion that ODT of volatile compounds in complex products cannot be predicted using ODT value determined in water, but must be determined in the specific emulsion system.

The storage condition, which led to the highest concentration of primary oxidation products (as measured by PV) was $20^{\circ} \mathrm{C}+$ light. For secondary oxidation products the conditions $20^{\circ} \mathrm{C}+$ light and elevated temperature accelerated the formation of several of the measured volatiles.

At elevated temperatures, it is hypothesised that primary oxidation products convert rapidly to secondary oxidation products and therefore primary oxidation products are not detected in the same relative abundance at elevated temperatures.

3-Methyl-1-butanol was the most impactful volatile on odour in both products. Therefore, it may be important to limit its formation and/or impact. This volatile was present initially and may therefore originate from one of the ingredients used. More studies are needed to identify the raw material(s) responsible for its presence.

\section{Literature}

[1] Moeglin, E. Scent trends in personal care \& household. Presentation at "In Cosmetics", Barcelona 2015.

[2] Woitalla, I. Fragrance in cosmetics the smell of success. Presentation at "In Cosmetics", Hamburg 2014.

[3] Patravale, V. B and Mandawgade, S. D. Novel cosmetic delivery systems: an application update. International J. of Cosmectic Science 2008, 30, 19-33.

[4] Carlotti, M. E., Gasco, M. R., Trotta, M. and Morel, S. J. Auto-oxidation of linoleic acid in cosmetic formulations. Soc. Cosmet. Chem. 1991, 42, 285-298.

[5] Waraho, T., McClements, D. J., Decker, E. A. Mechanisms of lipid oxidation in food dispersions. Trends Food Sci. Technol. 2011, 22, 3-13.

[6] Park, E. Y., Nakamura, Y., Sato, K. and Matsumura, Y. Effects of amino acids and peptide on lipid oxidation in emulsion systems. J. Am. Oil Chem. Soc. 2012, 89, 477-484.

[7] Nibbe, N., Gygax, H. and Maxeiner, B. Odour Measurement for Improved Scent Performance in Consumer Goods. SOFW-Journal 2015, 141, 42-46. 
[8] Hu M. and Jacobsen C. Oxidative Stability and Shelf Life of Foods Containing Oils and Fats. AOCS American Oil Chemists' Society. 2016.

[9] Malinowska, P., Gliszczynska-Swiglo, A. and Szymusiak, H. Protective effect of commercial acerola, willow and rose extracts against oxidation of cosmetic emulsions containing wheat germ oil. Eur. J. Lipid Sci. Technol. 2014, 116, 1553-1562.

[10] Balboa, E. M., Soto, M. L., Nogueira, D. R., González-Lopez, N., Conde, E., Moure, A., Vinardell, M. P., Mitjans, M. and Domíngues, H. Potential of antioxidant extracts produced by aqueous processing of renewable resources for the formulation of cosmetics. Industrial Crops and Products 2014, 58, 104-110.

[11] Thanonkaew, A., Wongyai, S., Decker, E. A. and McClements, D. J. Formation, antioxidant property and oxidative stability of cold pressed rice bran oil emulsion. J. Food Sci. Technol. 2015, 52(10), 6520-6528.

[12] Poyato, C., Thomsen, B. R., Hermund, D. B., Ansorena, D., Astiasaran, I., Jonsdottir, R., Kristinsson, H. G. and Jacobsen, C. Antioxidant effect of water and acetone extracts of Fucus vesiculosus on oxidative stability of skincare emulsions. Eur. J. Lipid Sci. Technol. 2016, accepted June.

[13] Thomsen, B. R., Horn, A. F., Hyldig, G., Taylor, R., Blenkiron, P. and Jacobsen, C. Investigation of lipid oxidation in high- and low-lipid-containing topical skin formulations. Submitted.

[14] Bligh E. G. and Dyer W. J. (1959). A rapid method of total lipid extraction and purification. Canadian Journal of Biochemistry and Physiology 37, 911-917.

[15] Iverson, S. J., Lang, S. L. C. and Coope, M. H.(2001). Comparison of the Bligh and Dyer and Folch Methods for Total Lipid Determination in a Broad Range of Marine Tissue. Lipids 36(11), 1283-1287.

[16] International IDF Standard 74 A (1991). Milk and Milk Products:Determination of the Iron Content, International Dairy Federation, Brussels.

[17] Thomsen, B. R., Yesiltas, B., Sørensen, A.-D. M., Hermund, D. B., Glastrup, J. and Jacobsen, C. Comparison of Three Methods for Extraction of Volatile Lipid Oxidation Products from Food Matrices for GC-MS Analysis. JAOCS. 2016, 93(7), 1-14.

[18] Fors, S. Sensory properties of volatile maillard reaction products and related compounds in the maillard reaction. Foods and nutrition ACS Symposium Series 1988, 215, 185-286.

[19] Buttery, B. G., J. G. Turnbaugh and L. C. Ling. Contribution of volatiles to rice aroma. J. Agric. Food Chem. 1988, 36(5), 1006-1009.

[20] Guadagni, G., Buttery, R G. and Okano, S. Odour thresholds of some organic compounds associated with food flavours. J. Sci. Food Agric. 1963, 14, 761-765.

[21] Fazzalari, F A., Compilation of Odor and Taste Threshold Data, ASTM Data Series DS 48A (1978). 
[22] Choe, E. and Min, D. B. Mechanisms and Factors for Edible Oil Oxidation. Comprehensive reviews in food and safety 2006, 5, 169-186.

[23] Takken, H. J., van der Linde, L. M., Boehlens, M. and van Dort, J. M. Olfactive properties of a number of polysubstituted pyrazines. J Agric. Food Chem. 1975, 23, 638-642.

[24] Teranishi, R., Buttery R. G. and Gaudagni, D. G. Odor quality and chemical structure in fruit and vegetable flavor. Annals New York Acad. Sci. 1974, 237, 209-216.

[25] Giri, A. Osaka, K. and Ohshima, T. Identification and characterisation of headspace volatiles of fish miso, a Japanese fish meat based fermented paste, with special emphasis on effect of fish species and meat washing. Food Chem. 2010, 120(10), 621-631.

[26] Kaseleht, K. Leitner, E. and Paalme, T. Determining aroma-active compounds in Kama flour using SPME-GC/MS and GC-olfactometry. Flavour Fragr. J. 2010, 26(2), 122-128.

[27] Buttery, R. G., Seifert, R. M., Guadagni, D. G. and Ling, L. C. Characterization of some volatile constituents of bell peppers. J. Agric. Food Chem. 1969, 17(6), 1322-1327.

[28] Butt Buttery, R. G., Teranishi, R., Flath, R. A. and Ling, L. C. Quantitative and sensory studies on tomato paste volatiles J. Agric. Food Chem. 1990, 38(1), 336-340.

[29] Acree, T. and Arn, H. Flavornet. Internet database: http://www.flavornet.org/flavornet.html. Accessed 28/6-2016.

[30] Fukami, K., Ishiyama, S., Yaguramaki, H., Masuzawa, T., Nabeta, Y., Endo, K., and Shimoda, M. Identification of distinctive volatile compounds in fish sauce. J. Agric. Food Chem. 2002, 50(19), 5412-5416.

[31] Giri, A., Osaka, K. and Ohshima, T. Identification and characterisation of headspace volatiles of fish miso, a Japanese fish meat based fermented paste, with special emphasis on effect of fish species and meat washing. Food Chem. 2010, 120, 621-631.

[32] Burdock, G. A. Fenaroli’s Handbook of Flavor Ingredients. 4th ed., CRC Press Inc. 2002, Boca Raton, FL, USA.

[33] Yan, Z., Xin, L., Chih, K. L. and Shun, T. G. Characterization of the volatile substances and aroma components from traditional soypaste. Molecules 2010, 15(5), 3421-3427.

[34] Costa, P., Velasco, C. V., Loureiro, J. M. and Rodrigues, A. E. Effect of cosmetic matrices on the release and odour profiles of the supercritical CO2 extract of Origanum majorana L.

International Journal of Cosmetic Science 2016, 38(4), 364-374.

[35] Venkateschwarlu G., Let M. B., Meyer A. S. and Jacobsen C. Modeling the sensory impact of defined combinations of volatile lipid oxidation products on fishy and metallic off-flavors. J. Agric. Food Chem. 2004, 52(6), 1635-1641.

[36] Laing, D. G. Perceptual odour interactions and objective mixture analysis. Food Quality and Preference 1994, 5, 75-80. 
Table 1. The lipid blends included and approximate lipid contents for Skin Cream Formulation and Cleansing Formulation Prototypes.

\begin{tabular}{|c|l|l|}
\hline Product & \multicolumn{1}{|c|}{ Skin Cream Formulation Prototype } & \multicolumn{1}{|c|}{ Cleansing Formulation Prototype } \\
\hline $\begin{array}{c}\text { A blend of the } \\
\text { following lipids }\end{array}$ & $\begin{array}{l}\text { Butyrospermum Parkii Butter, Isostearyl } \\
\text { Isostearate, Caprylic/Capric Triglyceride, Oryza } \\
\text { Sativa Cera and Squalane }\end{array}$ & $\begin{array}{l}\text { Caprylic/Capric Triglyceride, Cocos Nucifera } \\
\text { Oil, Olea Europaea Fruit Oil, Elaeis } \\
\text { Guineensis Oil, Olus Oil and Squalane }\end{array}$ \\
\hline Total Lipid Content & $\sim 15 \%$ (N.B. any organic UV filters not included) & $\sim 10 \%$ \\
\hline
\end{tabular}

Table 2. Concentrations (Conc.) applied to determine the odour detection threshold value in the Skin Cream Formulation Prototype for 2-ethyl furan, 2-pentyl furan, butanal, pentanal, 1-heptanol and 3-methyl-1-butanol. Conc. 1 is close to odour detection threshold value in water. The concentration is gradually increased in conc. 2-5 until the estimated odour detection threshold value in skin cream formulation prototype determined by an expert panel has been reached. Conc. 6 is above the estimated odour detection threshold value in skin cream formulation prototype.

\begin{tabular}{|l|l|l|l|l|l|l|}
\hline \multicolumn{7}{|c|}{ Concentration selected for Skin Cream Formulation Prototype } \\
\hline Volatile standard/ Conc. [ng/g] & Conc. 1 & Conc. 2 & Conc. 3 & Conc. 4 & Conc. 5 & Conc. 6 \\
\hline 2-ethyl furan & 10 & 20 & 30 & 40 & 55 & 70 \\
\hline 2-pentyl furan & 10 & 30 & 50 & 65 & 80 & 100 \\
\hline Butanal & 10 & 25 & 40 & 55 & 65 & 80 \\
\hline Pentanal & 10 & 30 & 50 & 65 & 80 & 100 \\
\hline 1-heptanol & 10 & 25 & 40 & 55 & 65 & 80 \\
\hline 3-methyl-1-butanol & 200 & 240 & 290 & 320 & 360 & 400 \\
\hline
\end{tabular}

Table 3. Concentrations (Conc.) applied to determine the odour detection threshold value in the Cleansing Formulation Prototype for 2-ethyl furan, 2-pentyl furan, butanal, pentanal, 1-heptanol and 3-methyl-1-butanol. Conc. 1 is close to odour detection threshold value in water. The concentration is gradually increased in conc. 2-5 until the estimated odour detection threshold value in cleansing formulation prototype determined by an expert panel has been reached. Conc. 6 is above the estimated odour detection threshold value in cleansing formulation prototype.

\begin{tabular}{|l|l|l|l|l|l|l|}
\hline \multicolumn{7}{|c|}{ Concentration selected for Cleansing Formulation Prototype } \\
\hline Volatile standard/ Conc. [ng/g] & Conc. 1 & Conc. 2 & Conc. 3 & Conc. 4 & Conc. 5 & Conc. 6 \\
\hline 2-ethyl furan & 10 & 20 & 30 & 40 & 55 & 70 \\
\hline 2-pentyl furan & 10 & 25 & 40 & 55 & 65 & 80 \\
\hline Butanal & 20 & 60 & 100 & 130 & 160 & 200 \\
\hline Pentanal & 10 & 25 & 40 & 55 & 65 & 80 \\
\hline 1-heptanol & 10 & 25 & 40 & 55 & 65 & 80 \\
\hline 3-methyl-1-butanol & 200 & 240 & 290 & 320 & 360 & 400 \\
\hline
\end{tabular}


Table 4. Odour description by the trained sensory panel of the six volatile standards when added to Skin Cream Formulation and Cleansing Formulation Prototypes.

\begin{tabular}{|l|l|l|}
\hline Volatile standard & \multicolumn{1}{|c|}{$\begin{array}{c}\text { Odour in Skin Cream Formulation } \\
\text { Prototype }\end{array}$} & \multicolumn{1}{|c|}{$\begin{array}{c}\text { Odour in Cleansing Formulation } \\
\text { Prototype }\end{array}$} \\
\hline $\begin{array}{l}\text { 3-methyl-1- } \\
\text { butanol }\end{array}$ & $\begin{array}{l}\text { Glue, rubber, chemical, } \\
\text { medicine, cleaning agent and } \\
\text { toilet cleaner }\end{array}$ & $\begin{array}{l}\text { Medicine, glue, sour dishcloth and } \\
\text { chemical }\end{array}$ \\
\hline 1-heptanol & $\begin{array}{l}\text { Perfume, lime / citrus juice, } \\
\text { sweet and coconut }\end{array}$ & $\begin{array}{l}\text { Coconut, dried banana, caramel } \\
\text { and condensed milk }\end{array}$ \\
\hline 2-ethyl- furan & $\begin{array}{l}\text { Stearin, white chocolate and } \\
\text { artificial vanilla }\end{array}$ & $\begin{array}{l}\text { Creme anglaise, artificial vanilla, } \\
\text { white chocolate and caramel }\end{array}$ \\
\hline 2-pentyl-furan & Mushroom, moss and soil & Soap flakes, liquorice and perfume \\
\hline Butanal & $\begin{array}{l}\text { Parmesan, sour dishcloth and } \\
\text { baby regurgitation }\end{array}$ & Parmesan, sour and sickly sweet \\
\hline Pentanal & Green and milk acidic & Flower, green and (willow) bark \\
\hline
\end{tabular}

Table 2. Odour detection threshold values for the Skin Cream Formulation and the Cleansing Formulation Prototypes.

\begin{tabular}{|c|c|c|c|c|}
\hline \multirow{2}{*}{ Volatile } & \multicolumn{2}{|c|}{$\begin{array}{l}\text { Skin Cream Formulation } \\
\text { Prototype }\end{array}$} & \multicolumn{2}{|c|}{$\begin{array}{l}\text { Cleansing Formulation } \\
\text { Prototype }\end{array}$} \\
\hline & $\begin{array}{l}\text { ODT avg } \\
\text { (added ng/g) }\end{array}$ & $\begin{array}{l}\text { GC-MS } \\
\text { (total ng/g) }\end{array}$ & $\begin{array}{l}\text { ODT avg } \\
\text { (added ng/g) }\end{array}$ & \begin{tabular}{|l} 
GC-MS \\
(total ng/g)
\end{tabular} \\
\hline 3-methyl-1-butanol & 315.65 & $1926 \pm 316$ & 203.1 & $394 \pm 17$ \\
\hline 1-heptanol & 56.05 & $155 \pm 24$ & 47.9 & $170 \pm 23$ \\
\hline 2-ethylfuran & 59.35 & $125 \pm 15$ & 52.65 & $75 \pm 9$ \\
\hline 2-pentylfuran & 77.6 & $79 \pm 13$ & 53.85 & $292 \pm 41$ \\
\hline Butanal & 46.2 & $72 \pm 3$ & 112.55 & $130 \pm 10$ \\
\hline Pentanal & 45.75 & $87 \pm 5$ & 19.9 & $100 \pm 6$ \\
\hline
\end{tabular}


A) Peroxide value

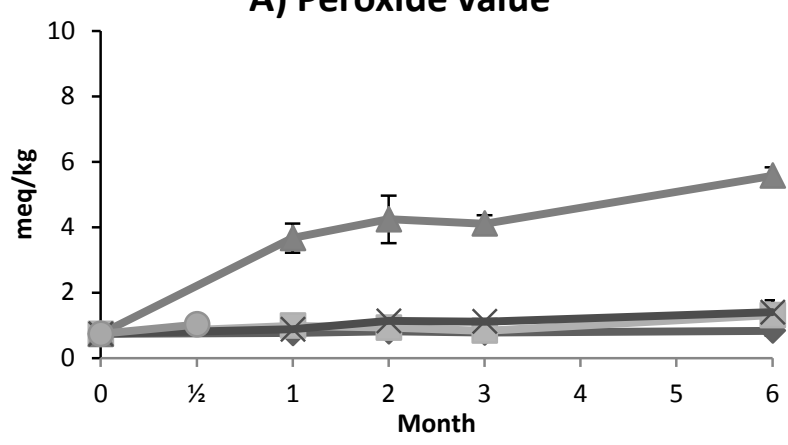

C) Pentanal

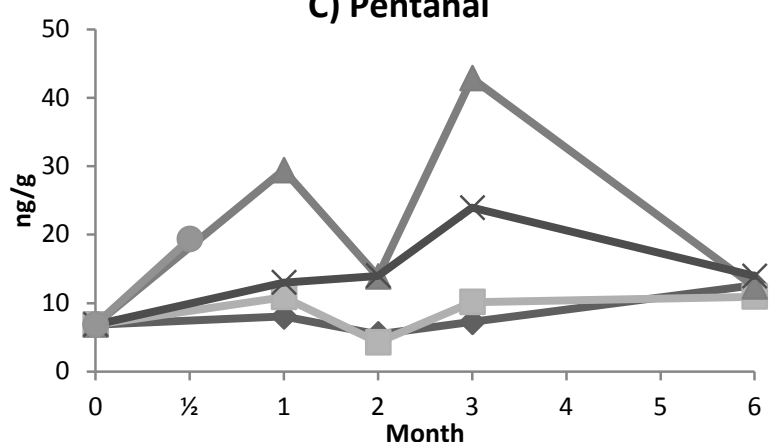

E) 2-pentyl furan

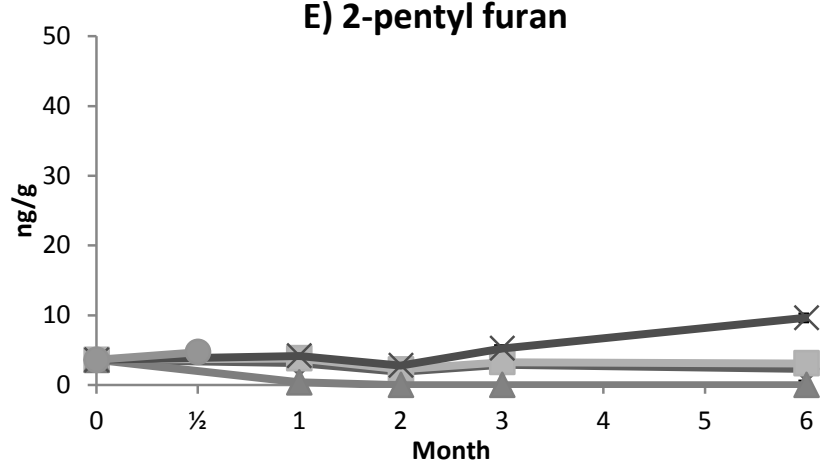

G) 1-heptanol

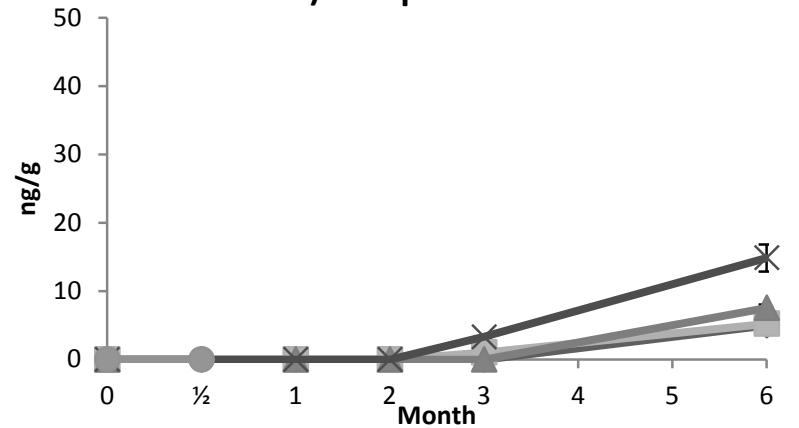

B) Butanal

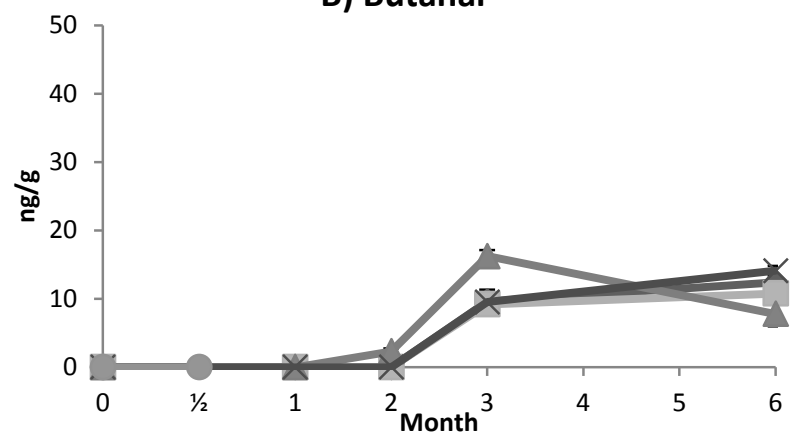

D) 2-ethyl furan

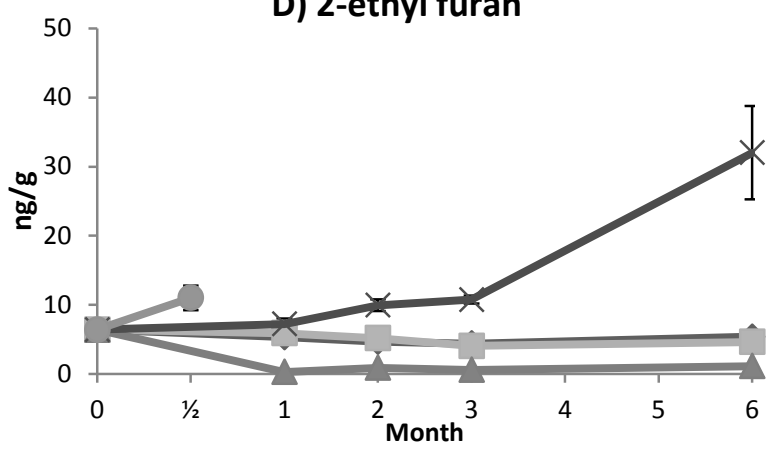

F) 3-methyl-1-butanol

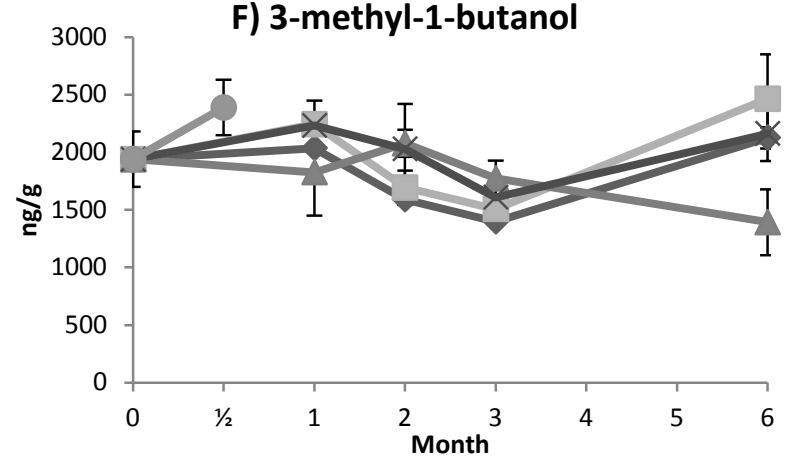

Figure 1. The progress of development of lipid oxidation products during 6 months of storage in Skin Cream Formulation Prototype under various storage conditions. The storage conditions are marked in the following way; $5^{\circ} \mathrm{C}(\bullet), 20^{\circ} \mathrm{C}(\square), 20+$ light $(\triangle), 40^{\circ} \mathrm{C}(\times)$ and $50^{\circ} \mathrm{C}(\odot)$. The development of $\left.A\right)$ peroxide value [meq/kg], B) butanal [ng/g], C) pentanal [ng/g], D) 2ethyl furan [ng/g], E) 2-pentyl furan [ng/g], F) 3-methyl-1-butanol during storage [ng/g], and G) 1-heptanol [ng/g] during storage. 

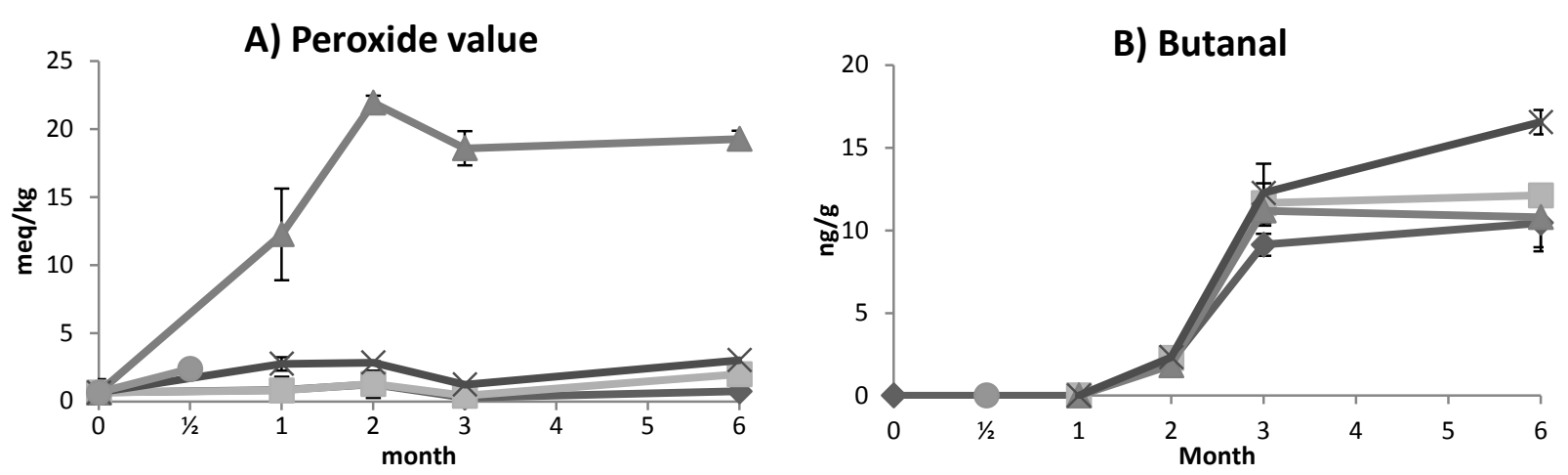

Figure 2. The progress of lipid oxidation in Cleansing Formulation Prototype during 6 months storage at various storage conditions. The storage conditions are marked in the following way; $5^{\circ} \mathrm{C}(\bullet), 20^{\circ} \mathrm{C}(\square), 20+$ light $(\triangle), 40^{\circ} \mathrm{C}(\times)$ and $50^{\circ} \mathrm{C}(O)$. The development of A) peroxide value [meq/kg], and B) butanal [ng/g] during storage. 